\title{
Personality, well-being and deprivation theory
}

Authors: Peter A. Creed and Bronwyn M. Evans School of Applied Psychology

Griffith University - Gold Coast

Contact: Dr Peter Creed

School of Applied Psychology

Griffith University - Gold Coast

PMB 50

Gold Coast Mail Centre 9726

Queensland

Australia

p.creed@mailbox.gu,edu.au 


\title{
Personality, well-being and deprivation theory
}

\begin{abstract}
Two hundred and thirty-eight university students were administered scales of the latent (social support, status, time use, collective purpose, activity) and manifest (financial) benefits of employment, the five main personality factors (neuroticism, extraversion, agreeability, conscientiousness, and intellect/openness), and psychological well-being. Results indicated that the latent and manifest benefits of employment were significantly associated with well-being in a student sample, that personality was able to account for a significant amount of the explained variance in well-being over and above the situational variables covered by the latent and manifest benefits, and that neuroticism was the main individual difference influencing well-being. The results were examined in the context of a bottom-up/top-down explanatory model of well-being, and recommendations are made regarding an expanded role for manifest benefits, and for the inclusion of personality variables in the latent deprivation model (Jahoda, 1982), the most influential situation model accounting for deterioration in well-being.
\end{abstract}

Key words: latent benefits, manifest benefits, well-being, neuroticism, latent deprivation model 
Over sixty years ago Jahoda, Lazarsfeld and Zeisel (1933) found that loss of employment was associated with a deterioration in a range of well-being indices. Research since that time has confirmed these results and demonstrated that the decline in well-being is largely the result of the unemployment experience and not the result of a disproportionate number of people with poorer well-being becoming unemployed (for recent reviews see Murphy \& Athanasou, 1999 and Winefield, 1995). The specific unemployment theory that has dominated the research and applied efforts to account for this decline in well-being is the latent deprivation model proposed by Jahoda (1981, 1982).

The latent deprivation model, which is conceptually derived from Merton's (1957) paradigm for functional analysis, specifically focuses on the loss of the manifest and latent functions of employment. According to the model, individuals engage in employment primarily for financial rewards (manifest functions) but also benefit from a number of latent by-products (latent functions), which are associated with the development and maintenance of psychological well-being. The five most important latent functions are the imposition of a time structure, regular shared social contact, the linking of individuals in a shared collective effort or purpose, the provision of a social identity or status, and regular enforced activity. At the core of the theory is the assumption that people have deep-seated psychological needs for the satisfaction of the latent functions and that these needs are best met in paid employment (Jahoda, 1984). When individuals lose their employment, not only do they lose the manifest functions of 
work (i.e., their income), they also are deprived of the latent functions of work, and it is the loss of the latent functions that impacts negatively on psychological well-being.

Despite the intuitive appeal of the latent deprivation model, a number of problems have been identified. Firstly, the empirical evidence suggests that, counter to the model, some individuals do not suffer psychologically while unemployed (Fryer \& McKenna, 1987; Hesketh, Shouksmith, \& Kang, 1987). In this context, it is supposed that these individuals have found functional alternatives to accessing the latent functions in order to satisfy their basic psychological needs. This indicates that, while unemployed, it is possible to access the latent functions from other sources, for example by continuing the pursuit of purposeful activity and maintaining regular contact with people outside the family.

Secondly, the empirical research has indicated that some latent functions are more important than others in relation to well-being. In particular, time structure and activity level (Haworth, 1986), and time structure, activity level and collective purpose (Creed \& Macintyre, 2001) have been shown to have stronger associations with well-being than the remaining latent functions.

Thirdly, the relative importance of the latent functions as opposed to the manifest functions has been an important consideration in the literature. While the Deprivation Model proposes that it is the loss of the latent functions that primarily accounts for a decline in well-being when the individual becomes unemployed, much empirical evidence (e.g., Whelan, 1992) and theorising (see Fryer, 1995) have demonstrated the 
importance of the loss the manifest functions and poverty in the decline in well-being in the unemployed.

Fourthly, associations between latent functions and well-being have been found for populations other than those drawn from labour market. For example, Jackson (1999) found that students fell somewhere in between unemployed and employed youth on levels of access to the latent functions and on levels of well-being. Rowe (2001) found associations between well-being and the latent functions in a sample of elderly retirees. These studies indicated that people outside of the labour market also have access to the latent functions, and that the levels of access in these samples account for much of the variance in well-being.

Fifthly, the latent deprivation view relies on the noble view that employment is universally beneficial to psychological well-being. The empirical evidence here, however, indicates that people do not experience work as universally satisfying or beneficial. Indeed, leaving dissatisfying and stressful work can produce improvements in well-being when the individual becomes unemployed (O'Brien, \& Feather 1990; Winefield, Tiggemann \& Winefield, 1992).

Lastly, the generalisation about the institution of work, that all paid employment is beneficial, fails to acknowledge that individuals perceive situational information biased by individual differences of personality and disposition. The Deprivation Model largely ignores the notion that people have different reactions to the same situations, and that they evaluate conditions based on their unique expectations, values, previous experiences and temperament (DeNeve \& Cooper, 1998; Ezzy, 1993). Therefore, to provide a more 
coherent explanation of well-being the model must give consideration to the individual differences that people bring to a life situation, in the same way that other models attempt to (Diener, Suh, Lucas, \& Smith, 1999).

Early models of well-being concentrated on identifying the requisite needs for happiness. The assumption was that the timely satisfaction of these needs resulted in happiness, and that the persistence of unmet needs resulted in unhappiness (Wilson, 1967). The focus was largely on situational factors forming a bottom-up approach to explaining well-being (DeNeve \& Cooper, 1998). One of the situational factors examined in this way is unemployment. More recent models have placed an emphasis on identifying the role of internal processes or individual differences in well-being. This has resulted from the repeated discovery that objective circumstances do not generally account for much of the variance associated with well-being. Costa and McCrae (1980) reported that the effect size for external, objective variables is small, accounting for no more than $20 \%$ in the best instance. In a recent study, Kozma, Stone and Stones (1999) explored the relationship between stability in well-being and stability in the environment. They found that all factors examined contributed somewhat, however stability in the environment made the smallest contribution.

Diener et al., (1999) describe the shift from external elements to personal aspects as an important theoretical advance. Known as top-down approaches, these models focus on structures within the person, particularly personality traits that determine how that person perceives events and circumstances to explain well-being. While this paper has a focus on personality factors, it should also be noted that other factors such as individual 
cognitions, goals, culture and adaptation coping efforts all moderate the influence of life circumstances and events on well-being. Personality factors are considered one of the strongest and most consistent predictors of well-being, with evidence coming from a variety of research methodologies and large number of studies (DeNeve \& Cooper, 1998). Top-down approaches stress the importance of stable personality traits that work on a global level and create a tendency to experience life in a positive or negative manner. This global tendency influences the interpretation of momentary events resulting in a propensity to interpret events in a particular manner that changes little over different life situations (Campbell, Converse, \& Rodgers, 1976).

The personality traits given the most attention in this regard are extraversion and neuroticism. A number of researchers have shown a strong relationship between extraversion and positive affect, and between neuroticism and negative affect (e.g., David, Green, Martin, \& Suls, 1997; Watson \& Clarke, 1997). Costa and McCrae (1980) originally proposed that extraversion led to positive affect and neuroticism led to negative affect. They later revised their model to include a temperament and instrumental view of the relationship between personality and well-being (McCrae \& Costa, 1991). The temperament view suggests that certain personality traits, such as extraversion and neuroticism, represent enduring cognitive dispositions that directly affect well-being. Other personality traits, such as agreeableness and conscientiousness, have an indirect or instrumental role, which lead people to encounter specific situations that in turn affect well-being. 
Given this evidence, it is likely that the latent deprivation model, which is an example of a bottom-up theory that relies on situational factors rather than internal processes, would benefit from the inclusion of personality variables as factors influencing wellbeing. Jahoda (1984) herself conceded that the theory would benefit from recognising the interplay of "individual potentialities", and Creed, Muller and Machin (2001) have demonstrated that neuroticism can account for much of the variance in well-being in unemployed people.

The primary aim of this paper is to expand the latent deprivation model as a conceptualisation of well-being by firstly testing its usefulness with a student population, and secondly, testing the influence that personality dimensions contribute beyond the current situational approach. This second aim has not been attempted to date even though supporters of such an expanded model agree that it would benefit from this treatment (Ezzy, 1993; Feather, 1997; Fryer, 1995; Jahoda, 1984). In line with earlier evidence that the latent deprivation model can explain well-being in non-labour market populations, Hypothesis 1 is that access to the latent and manifest functions will be associated with well-being in student population. To test the differing contributions of bottom-up and top-down approaches to well-being, Hypothesis 2 is that personality factors will account for a significant proportion of the variance when explaining well-being after the latent and manifest functions have been accounted for. A positive outcome here would support prior research that individual factors contribute to well-being beyond situational factors. In keeping with the pre-eminent role demonstrated previously for neuroticism and extraversion, Hypothesis 3 is that that neuroticism and extraversion will have a stronger 
direct influence on well-being than other major personality dimensions (of conscientiousness, agreeability and intellect).

\section{Method}

\section{Participants}

Participants were 238 first year university students, $71 \%$ female, with a mean age of $23.69(S D=8.24)$

\section{Materials}

The 15-item Access to Categories of Experience scale (ACE; Evans, 1986) was utilised as a measure of the five latent benefits of employment (of activity, time structure, social contact, status and collective purpose). The scale consists of three items for each latent benefit, with sample items of "Time often lies heavy on my hands" (activity), "I'm doing things that need doing by someone" (collective purpose), "I very rarely ever need to be punctual" (time structure), "Most days I meet quite a range of people" (social support), and "Sometimes I feel like I'm on the scrapheap" (status). Respondents were asked to indicate their agreement with the statements on a seven-point scale with endpoints of "completely agree" and "completely disagree". Higher scores indicate greater access to the benefits of employment. Creed and Machin (Submitted), who have examined the psychometric properties of the ACE, recommend that the scale be used as a global measure, rather than it be examined using the five sub-scales. These authors reported an internal reliability coefficient for the ACE of 0.80 with a large sample of 
unemployed people. In the present study, the internal reliability coefficient was 0.75 . Evans and Banks (1992) report divergent validity data based on discriminating the ACE environmental measures from affective measures.

A four-item Financial Strain scale (FS), which has been widely used in occupational studies (Ullah, 1990; Warr \& Jackson 1987), was utilised as a measure of the manifest benefit of employment. Respondents were asked to consider how often in the last month they had had serious financial worries, not been able to do things they like to do because of money, not been able to do the things they need to do because of money, and been able to manage on the money they have. Responses were indicated on a five-point scale with end-points of "never" and "all the Time". Higher scores represented greater FS. The internal reliability coefficient for this sample was 0.87 .

The 12-item version of the General Health Questionnaire (GHQ; Goldberg, 1972) was utilised as a global measure of psychological distress. This version has been widely used and recommended for use as a screening device in occupational settings (e.g., Warr, 1987). Respondents were asked to report on how they felt recently on a range of variables, including cognitive processing, self esteem, anxiety and depression, for example "Have you recently been able to concentrate on whatever you're doing?". Responses were scored on a four-point scale from zero to three using anchors such as "better than usual/same as usual/less than usual/much more than usual". Higher scores indicated greater psychological distress. Goldberg and Williams (1988) reported a mean internal consistency of 0.85 . In the present study, the internal reliability coefficient was 0.86 . 
The Transparent Bipolar Inventory (TBI; Goldberg, 1992) was utilised as a measure of the five personality factors of surgency/extraversion, stability/neuroticism, intellect/openness, conscientiousness and agreeability. The TBI contains 50 bipolar descriptors, with 10 descriptors for each of the five personality traits. Sample items were "unenthusiastic-enthusiastic" (where "unenthusiastic" was one bipolar descriptor and "enthusiastic" was the other for the personality domain of surgency/extraversion), "stable-unstable" (stability/neuroticism), "curious-uninquisitive" (intellect/openness), "reliable-undependable" (conscientious), and "sociable-unsociable" (agreeableness). Items were randomly sequenced and desirable poles were split evenly between opposite sides of the page. Responses were scored on a nine-point scale, with higher scores representing more of a particular trait. Goldberg has provided validity data on the TBI, and reported internal reliability coefficients for the five factors ranging from $0.84-0.88$. Internal reliability coefficients in the present study were 0.79 (surgency/extraversion), 0.74 (agreeableness), 0.68 (conscientiousness), 0.76 (stability/neuroticism) and 0.71 (intellect/openness).

\section{Procedure}

Students were recruited by the second author from lectures and the campus in general. They were administered a survey form containing the ACE, FS, GHQ-12, TBI scales and questions related to age and gender. 


\section{Results}

\section{Latent and manifest functions and well-being in a student sample}

Summary data and bivariate correlations among all variables are reported in Table 1. Meaningful correlations $(\geq 0.33$, where the shared variance is greater than $10 \%$, Tabachnik \& Fidell, 1996) were found between the global ACE score and GHQ-12, and between FS and GHQ-12, such that greater access to the latent and manifest functions was associated with better well-being. These correlations support Hypothesis 1, that latent (ACE) and manifest (FS) functions would be significantly associated with wellbeing (GHQ-12) in a student sample. The global ACE score was also meaningfully correlated with the personality variables of TBI-N, TBI-E, TBI-C and TBI-I, indicating that while there is some overlap between the ACE and personality constructs, the ACE scale is measuring something other than temperament. Also here, those reporting more access to the latent benefits (ACE) were more likely to have higher levels of neuroticism, extraversion, conscientiousness and openness. FS and GHQ-12 were also meaningfully associated with TBI-I, indicating that those reporting more openness were experiencing less financial strain and higher levels of well-being. There were largely low intercorrelations among the five personality dimensions confirming independence, and there were no meaningful correlations with age or gender. 
Table 1

Means and Standard Deviations for Access to Categories of Experience scale, Financial Strain scale, General Health Questionnaire, Transparent Bipolar Inventory and Age. $N=238$.

\begin{tabular}{|c|c|c|c|c|c|c|c|c|c|c|c|c|}
\hline Variable & M & SD & 1 & 2 & 3 & 4 & 5 & 6 & 7 & 8 & 9 & 10 \\
\hline 1. ACE & 54.35 & 7.44 & - & $-.17 * *$ & $-.37 * * *$ & $.30 * * *$ & $.50 * * *$ & $.34 * * *$ & $.36 * * *$ & $.36^{* * *}$ & $.14^{*}$ & -.02 \\
\hline 2. FS & 8.76 & 3.79 & & - & $.45 * * *$ & -.06 & -.12 & -.13 & .02 & $-.34 * * *$ & .01 & -.03 \\
\hline 3. GHQ-12 & 11.73 & 6.00 & & & - & $-.22 * * *$ & $-.30 * * *$ & $-.21 * *$ & $-.17 * *$ & $-.53 * * *$ & -.01 & -.08 \\
\hline 4. TBI - A & 69.36 & 9.50 & & & & - & $.23 * * *$ & $.40 * * *$ & $.32 * * *$ & $.32 * * *$ & .12 & .04 \\
\hline 5. TBI - N & 53.26 & 11.30 & & & & & - & .10 & $.31 * * *$ & $.35 * * *$ & -.12 & -.03 \\
\hline 6. TBI - E & 62.50 & 11.10 & & & & & & - & $.29 * * *$ & $.27 * * *$ & $.27 * * *$ & -.10 \\
\hline 7. TBI - C & 63.50 & 9.94 & & & & & & & - & .07 & $.21 * *$ & $.14^{*}$ \\
\hline 8. TBI - I & 66.68 & 8.65 & & & & & & & & - & .07 & .08 \\
\hline 9. Age & 23.69 & 8.24 & & & & & & & & & - & .06 \\
\hline
\end{tabular}

Note: ACE $=15$-item Access to Categories of Experience scale; FS = 4-item Financial Strain scale; GHQ-12=12-item General Health Questionnaire; TBI = Transparent Bipolar Inventory; A = TBI Agreeability subscale; $\mathrm{N}=$ TBI Stability/Neuroticism subscale; $\mathrm{E}=$ TBI Surgency/Extraversion subscale; $\mathrm{C}=$ TBI Conscientiousness subscale; $\mathrm{I}=\mathrm{TBI}$ Intellect/Openness subscale. 


\section{Latent and manifest functions and personality}

An hierarchical multiple regression analysis was conducted to test Hypothesis 2, that personality factors would account for a significant proportion of the variance in well-being after the latent and manifest functions have been accounted for. FS was entered as the first step in the analysis; ACE was entered as the second step; and the personality variables TBI (A, N, E, C and I) were entered as the third step. GHQ-12 was used as the dependent variable. Summary statistics are presented in Table 2.

The results here supported Hypothesis 2. The analysis shows that taken together the variables account for $40 \%$ of the variance in psychological well-being. FS significantly predicted psychological distress, $F(1,236)=58.39, p<.001$ (Model 1), and accounted for $20 \%$ of the variance in GHQ-12. Adding ACE to the regression equation was also able to significantly predict psychological distress, $F(2,235)=47.78, p<.001$ (Model 2), and to account for an additional $9 \%$ of the variance of GHQ-12. Adding the personality variables TBI (A, N, E, C and I) to the equation was also able to significantly predict psychological distress, $F(7,230)=21.85, p<.001$ (Model 3), and to account for a further $11 \%$ of the variance. In partial support of Hypothesis 3, which was that neuroticism and extraversion would have a stronger direct influence on well-being than conscientiousness, agreeability and intellect, the only personality variable to make a significant individual contribution was TBI$\mathrm{N}$, neuroticism $(\beta=-0.35)$. Students who were low on neuroticism experienced higher levels of well-being. 
Table 2

Summary of Hierarchical Multiple Regression Analysis for Variables Predicting Psychological Distress (GHQ-12) (N=238).

Variable

B

SE B

$\beta$

Step 1

FS

0.71

0.09

$0.45 * * *$

Step 2

ACE

$-0.25$

0.05

$-0.31 * * *$

Step 3

TBI-A

$-0.01$

0.04

$-0.01$

TBI-N

$-0.19$

0.03

$-0.35 * * *$

TBI-E

$-0.02$

0.03

$-0.03$

TBI-C

0.01

0.04

0.01

TBI-I

$-0.07$

0.04

$-0.10$

Note: $R^{2}=.20$ for Step $1 ; R^{2}$ Change $=.09$ for Step $2 ; R^{2}$ Change $=.11$ for Step $3 ;$ $* * *=p<.001$. Refer Table 1 for legend 


\section{Discussion}

The evidence from this study was that access to both the latent and manifest functions was associated with well-being in a university student sample, demonstrating that the latent deprivation model is useful in explaining well-being in non-labour market populations. Jahoda's (1982) original notion contended that latent functions cannot be adequately accessed outside a paid work situation, or that the energy required to do so is inordinate. This confirms previous findings that students can access the latent functions and that they do benefit from this access (Creed, Muller \& Machin, 2001; Jackson, 1999). It follows from this that if access to latent functions are not confined to the work place, the latent deprivation model may better be able to be reconceptualised as a model of access to daily situational experiences rather than solely work experiences. In this light, experiences of time structure, activity level, social contact, status, and collective purpose, as they occur in daily life inside or outside of the work domain can be sources of well-being.

Nonetheless, even though the relationship between well-being and the latent functions is significant, the actual correlation between the two is low. This is in keeping with other research on situational or bottom-up approaches to well-being. Objective circumstances continue to account for only small parts of the variance associated with well-being.

While this study has focused primarily on the latent functions within the latent deprivation model rather than on the manifest functions, stronger associations were found between the manifest functions and well-being (20\% shared variance) than between the latent functions and well-being (14\% shared variance). Jahoda (1982) maintained that the pursuit of financial 
gain was a transparent objective of paid employment, but that it was having the latent psychological needs met that was more important to well-being. This needs to be reconsidered in the light of the current findings. This evidence supports those who argue that financial deprivation and strain are the more important of the two functions in explaining psychological well-being. Fryer's explanation (cf. Fryer, 1995) for example, is that it is uncertainty about the future and financial insecurity caused by reduced actual or relative financial resources that accounts for deteriorating well-being.

In relation to personality, as expected from a top-down explanation of well-being, the evidence here was that personality does play a role in accounting for well-being over and above the explanation provided by the latent and manifest functions. Further, in this application it was the influence of neuroticism that contributed most to the effect. Given the direct relationship between neuroticism and negative affect it is likely that well-being is influenced by the way individuals view negative daily events. For example, those with low levels of neuroticism are less likely to view negative life events as catastrophic, and thus less likely to respond with lower levels of psychological well-being.

In this study, extraversion did not make a significant individual contribution to the model, despite previous research confirming its effect on positive affect and therefore on well-being. $\mathrm{Lu}$ (1999), in a study of personal and environmental causes of happiness, found that the effect of extraversion on well-being was mediated by social support. Social support was included in this study as one of the latent functions, and it may well have operated in a similar way to restrict the influence of extraversion. Future studies will need to examine the contribution of personality alongside the contributions of the individual latent functions, 
rather than the contributions of the latent functions as a global score, as was done in this study.

In summary, the latent functions have a weak but significant correlation with well-being in this student sample, and the manifest function has a significant moderate correlation. The performance of the manifest function implies that it should attract greater attention within the latent deprivation model. The significance of personality factors after accounting for manifest and latent functions indicates that the model would increase its predictive power by incorporating both situational and personality variables. A rationale for this has been provided by an examination of the bottom-up/top-down approaches to well-being. Future studies need to use robust measures of the individual latent and manifest functions (cf. Creed \& Machin, Submitted). They will need to test models that incorporate the influences of individual differences on the perception of situational variables, and on the perception of the interaction among these situational variables. In particular they will need to examine the interaction of the important role of financial strain and the latent functions. Further, many studies in this area have been cross-sectional, and longitudinal studies need to be constructed to be able to tease out causative effects of deteriorating well-being related to the latent and manifest functions. 


\section{References}

Campbell, A., Converse, P. E., \& Rodgers, W. L. (1976). The quality of American life. New York: Russell Sage Foundation.

Costa, P. T., \& McCrae, R. R. (1980). Influence of extraversion and neuroticism on subjective well-being: happy and unhappy people. Journal of Personality and Social Psychology, 38(4), 668-678.

Creed, P. A., \& Machin, M. A. (Submitted). Multidimensional properties of the Access to Categories of Experience scale.

Creed, P. A., \& Macintyre, S. R. (2001). The relative effects of deprivation of the latent and manifest benefits of employment on the wellbeing of unemployed people. Journal of Occupational Health Psychology, 64(4), 324-331.

Creed, P. A., Muller, J., \& Machin, M. A. (2001). The role of satisfaction with occupational status, neuroticism, financial strain and categories of experience in predicting mental health in the unemployed. Journal of Personality and Individual Differences, 30, 435447.

David, J. P., Green, P. R., Martin, R., \& Suls, J. (1997). Differential roles of neuroticism, extraversion and event desirability for mood in daily life: an integrative model of top-down and bottom-up influences. Journal of Personality and Social Psychology, 73(1), 149-159.

DeNeve, K. M., \& Cooper, H. (1998). The happy personality: a meta-analysis of 137 personality traits and subjective well-being. Psychological Bulletin, 124(2), 197-230. 
Diener, E., Suh, E., Lucas, R., \& Smith, H. (1999). Subjective well-being: Three decades of progress. Psychological Bulletin, 125(2), 276-302.

Evans, S. T. (1986). Variations in activity and psychological well-being in employed young adults. Unpublished doctoral dissertation, University of Manchester.

Evans, S. T., \& Banks, M. H. (1992). Latent functions of employment: Variations according to employment status and labor market. In C. H. A. Varhaar \& L. G. Jansma (Eds.). On the mysteries of unemployment (pp. 281-295). Dordrecht, Netherlands: Kluwer Academic.

Ezzy, D. (1993). Unemployment and mental health: a critical review. Social Science Medicine, 37(1), 41-52.

Feather, N. T. (1997). Economic deprivation and the psychological impact of being unemployed. Australian Psychologist, 32(1), 37-45.

Fryer, D. M. (1995). Benefit agency? Labour market disadvantage, deprivation and mental health. The Psychologist, June, 265-272.

Fryer, D. M., \& McKenna, S. P. (1987). The laying off of hands: Unemployment and the experience of time. In S. Fineman (Ed.). Unemployment: Personal and social consequences, (pp. 47-73). London: Tavistock.

Goldberg, D. (1972). The detection of psychiatric illness by questionnaire. Oxford: Oxford University Press.

Goldberg, D. P., \& Williams, P. (1988). A Users Guide to the General Health Questionnaire. Berkshire: NFER-NELSON. 
Goldberg, L. (1992). The development of markers for the big-five factor structure. Psychological Assessment, 4(1), 26-42.

Haworth, J. T. (1997). Work, leisure and well-being. London: Routledge.

Haworth, J. T. (1986). Meaningful activity and psychological models of non-employment. Leisure Studies, 5, 281-297.

Hesketh, B., Shouksmith, G., \& Kang, J. (1987). A case study and balance sheet approach to unemployment. Journal of Counseling and Development, 66, 175-179.

Jackson, T. (1999). Differences in psychological experiences of employed, unemployed, and student samples of young adults. The Journal of Psychology, 133(1), 49-59.

Jahoda, M. (1981). Work, employment, and unemployment: values, theories and approaches in social research. American Psychologist, 36, 184-191.

Jahoda, M. (1982). Employment and Unemployment. Cambridge: Cambridge University Press.

Jahoda, M. (1984). Social institutions and human needs: a comment on Fryer and Payne. Leisure Studies, 3, 297-299.

Jahoda, M., Lazarsfeld, P. F., \& Zeisel, H. (1933). Marienthal: The sociography of an unemployed community. (English translation, 1972). London: Tavistock Publications.

Kozma, A., Stone, S., \& Stones, M. J. (1999). Stability in components and predictors of subjective well-being (SWB): implications for SWB structure. Journal of Personality and Social Psychology, 69(1), 152-161.

Lu, L. (1999). Personal or environmental causes of happiness: a longitudinal analysis. Journal of Social Psychology, 139(1), 79-87. 
McCrae, R. R., \& Costa, P. T. (1991). Adding liebe und arbeit: the full five factor model of well-being. Personality and Social Psychology Bulletin, 17, 227-232.

Merton, R. K. (1957). Social theory and social structure. Chicago: Free Press of Glencoe.

Murphy, G. C. \& Athanasou, J. (1999). The effect of unemployment on mental health. Journal of Occupational and Organizational Psychology, 72, 83-99.

O’Brien,G. E., \& Feather, N. T. (1990). The relative effects of unemployment and quality of employment on the affect, work values and personal control of adolescents. Journal of Occupational Psychology, 63, 151-165.

Rowe, K. (2001). The role of latent and manifest functions in predicting well-being in a sample of retirees. Unpublished thesis dissertation. Griffith University, Gold Coast.

Tabachnik, B. G., \& Fidell, L. S. (1996). Using Multivariate Statistics. New York: HarperCollins College Publishers.

Ullah, P. (1990). The association between income, financial strain and psychological wellbeing among unemployed youths. Journal of Occupational Psychology, 63, 317-330.

Warr, P. B. (1987). Work, unemployment and mental health. Oxford: Oxford University Press.

Warr,P., \& Jackson, P. (1987). Adapting to the unemployed role: a longitudinal investigation. Social Science and Medicine, 25, 1219-1224.

Watson, D., \& Clark, L. A. (1997). Extraversion and its positive emotional core. In R. Hogan, J. Johnson \& S. Briggs (Eds.). Handbook of personality psychology, (pp. 767-793). San Diego: Academic Press. 
Whelan, C. T. (1992). The role of income, life-style deprivation and financial strain in mediating the impact of unemployment on psychological distress: Evidence from the Republic of Ireland. Journal of Occupational and Organizational Psychology, 65, 331-344.

Wilson, W. (1967). Correlates of avowed happiness. Psychological Bulletin, 67, 294-306.

Winefield, A. H. (1995). Unemployment: Its psychological costs. In C. L. Cooper \& I. T. Robertson (Eds.). International Review of Industrial and Organizational Psychology. Chichester: Wiley.

Winefield, A.H., Tiggemann, M., \& Winefield, H. R. (1992). Spare time use and psychological well-being in employed and unemployed young people. Journal of Occupational and Organizational Psychology, 65, 307-313. 